\title{
Opportunity Exploitation in Software Startups. A Human Capital View
}

\author{
Pertti Seppänen, Kari Liukkunen, Markku Oivo \\ M3S/M Group \\ University of Oulu, FI 90015 Oulu, Finland \\ \{pertti.seppanen, kari.liukkunen, markku.oivo\}@oulu.fi
}

\begin{abstract}
Background - Transforming a business opportunity to a valid business case is a crucial process of an early-stage software startups. Prior literature on entrepreneurship defines two types of opportunity exploitations, opportunity discovery and creation, and proposes models describing the exploitation processes. The factors affecting a startups abilities to conduct the exploitation are, however, addressed only to a limited extend. Aim - This research aims at increasing the knowledge on those factors by studying empirically the effects of the available human capital on the opportunity exploitation processes in software startups. Method - We conducted a multiple-case study on a group of software startups in Italy, Norway and Finland. We focused on the founders of the startups, examining their opportunity processes, their human capital, and the interdependencies between the opportunity processes and human capital. Results - Our results reveal that both opportunity discovery and creation processes coexist in the early stages of software startups, independently of how the opportunity was initially recognized. The results confirm the findings of the prior research, which point out that uncertainty is the key differentiator between the process types. They also highlight missing human capital as a key reason for the uncertainty. We conclude that in software startups the availability of human capital plays a bigger role in the exploitation of opportunities than their types, discovered or created, because even exploitation of a-priori existing opportunities turn to opportunity creation processes in case of human capital shortages.
\end{abstract}

Keywords: Software startup · Opportunity discovery theory $\cdot$ Opportunity creation theory $\cdot$ Product development process $\cdot$ Human capital theory

\section{Introduction}

Founding a software startup is a realization of a business opportunity. Identifying an opportunity, innovating a product or service fitting to the opportunity, and being able to turn the innovation to a business case are crucial tasks of an early-stage software startup. The phenomena of opportunity exploitation have been studied from the perspectives of business case creation by several authors. Alvarez et al. [1,2] presented the opportunity discovery and creation theories, and Sarasvathy [3] the effectuation theory. Ries [4], Bosch [5], and Ojala [6] propose startup models describing the processes of a successful business case creation. 
The opportunity discovery theory focuses on opportunities that exist independently of direct human involvement, waiting to be discovered by alert individuals or teams [1, 2]. The opportunity creation theory, in turn, suggests that new opportunities are created by individuals or teams working actively to initiate new businesses [1, 2], instead of just looking for existing opportunities. The effectuation theory focuses on phenomena caused by the unavoidable uncertainty of building up a new enterprise [3].

The theories [1-3] and the models [4-6] address the exploitation of opportunities by focusing on the innovations and the processes to create business cases, paying less attention to the new enterprise's abilities to conduct the exploitation processes. That leaves a gap in knowledge, what are the factors affecting these abilities. In this research, we studied the opportunity exploitation in software startups from the viewpoint of the human capital [7]. We opted for human capital (HC) because it was identified as a key contributor of startups' business performance in the prior literature on entrepreneurship [7-9].

For this study, we divided the human capital into three broad dimensions, human capital in business, human capital in software, and human capital in application technology. We defined the application technology as all other technology areas but software, used to implement the product.

The research was conducted on eleven startups in four European locations. We identified the characteristics of the startups' opportunity exploitation processes, defined the founders' human capital, and studied how the human capital affects the exploitation processes.

For our study, we asked the following research questions:

RQ1: What are the characteristics of the software startups' opportunity exploitation processes?

RQ2: What are the effects of the founders' human capital on the opportunity exploitation processes?

Our results indicate that, independently of the circumstances how the opportunity originally appeared, the opportunity exploitation in software startups is a process where 1) the characteristics of both opportunity creation and discovery co-exist, 2) the founders take actions typical for one or another theory on a context-dependent and situational basis, 3) a determining factor of the process type is the uncertainty, and 4) the human capital is both an origin of, and a means to manage, the uncertainty.

The rest of this paper is structured as follows. Section 2 focuses on the background of and the motivation for the study, reviewing prior research on the opportunity discovery and creation theories and the HC theory. Section 3 presents the research design, including the case selection and research data analysis. Section 4 deals with the results, and Section 5 discusses the study's findings and relevance. Section 6 concludes the paper and offers suggestions for future research.

\section{Background}

In this section, we review prior research on the opportunity exploitation and the human capital in order to gather the theoretical basis for our empirical study. This study is 
based on theories of opportunity creation and opportunity discovery, as defined by Alvarez and Barney in [1], Alvarez et al. in [2], and by Sarasvathy in [3, 10], and on the human capital theory as defined by Becker in [7].

\subsection{Prior Research on Opportunity Discovery and Opportunity Creation}

The opportunity discovery theory $[1,2]$ assumes that business opportunities exist as objective phenomena, just waiting for getting discovered. The theory proposes that such opportunities are generated autonomously by changes in competitive imperfections that in turn are based on changes in the business environment. Discovering new business opportunities created by such changes is then depending on an individual's abilities to discover them, on the individual's 'alertness' to the opportunities.

The prior existence of opportunities enables the alert individuals or teams to figure out a product or service addressing the discovered opportunity $[1,2]$. The predictability of the exploitation outcome is the key attribute of the discovery theory, out of which its other characteristics derive.

The opportunity creation theory, in turn, proposes that opportunities can be created by actions of individuals or teams $[1,2]$. The creation theory proposes that the opportunity creation process itself is the driving force that changes the business environment. It creates totally new customer demands or markets, and creates a slot in the business environment for the new product or service $[1,2]$. The non-existence of a prior competitive imperfection means that the outcome of the opportunity creation process cannot be defined in advance. Like the predictability of the exploitation outcome is the key of the discovery theory, the uncertainty of the outcome is the key of the opportunity creation theory.

The key differences of the theories are presented in table 1.

Table 1. General assumptions of opportunity discovery and creation theories [1]

\begin{tabular}{|c|c|c|}
\hline & Opportunity discovery & Opportunity creation \\
\hline Nature of opportunities & $\begin{array}{l}\text { Opportunities exist } \\
\text { independently of entrepreneurs }\end{array}$ & $\begin{array}{l}\text { Opportunities don't exist } \\
\text { independently of entrepreneurs }\end{array}$ \\
\hline Nature of entrepreneurs & $\begin{array}{l}\text { Differs from non-entrepreneurs } \\
\text { in advance by being more 'alert' } \\
\text { for the opportunities }\end{array}$ & $\begin{array}{l}\text { Do not necessarily differ from } \\
\text { non-entrepreneurs in advance }\end{array}$ \\
\hline $\begin{array}{l}\text { Nature of decision making } \\
\text { context }\end{array}$ & Risky & Uncertain \\
\hline Decision making & $\begin{array}{l}\text { Decisions based on risk } \\
\text { evaluations }\end{array}$ & $\begin{array}{l}\text { Iterative, inductive, and } \\
\text { incremental decision making }\end{array}$ \\
\hline Human resource practices & $\begin{array}{l}\text { Recruitment of task-specific } \\
\text { human capital }\end{array}$ & $\begin{array}{l}\text { Recruitment of general and } \\
\text { flexible human capital }\end{array}$ \\
\hline
\end{tabular}

Sarasvathy studied creation of new firms in [3], and defined an approach of human reasoning to address the uncertainty of the creation process, effectuation, as an opposite of a more traditional causation. She defines effectuation as on actor-dependent process, where the goal is to tackle contingences instead of reaching a pre-defined or known target $[3,10]$. Causation, in turn, is a reasoning process driven by a pre-defined target. 
The means to reach the target and their selection criteria are defined to fit the target [3, 10]. The key differences of causation and effectuation are presented in table 2.

Table 2. Selected differences of causation and effectuation [3]

\begin{tabular}{|l|l|l|}
\hline \multicolumn{2}{|l|}{ Causation } & Effectuation \\
\hline Target & Target is known & $\begin{array}{l}\text { Aspirations of possible targets, } \\
\text { means for striving for the target }\end{array}$ \\
\hline Decision making criteria & $\begin{array}{l}\text { Criteria helping to choose } \\
\text { between means to achieve the } \\
\text { target }\end{array}$ & $\begin{array}{l}\text { Criteria helping to choose } \\
\text { between alternatives provided } \\
\text { by the available means }\end{array}$ \\
\hline Competencies employed & $\begin{array}{l}\text { Focusing on utilizing } \\
\text { knowledge }\end{array}$ & $\begin{array}{l}\text { Focusing on exploiting } \\
\text { possibilities }\end{array}$ \\
\hline Nature of unknowns & $\begin{array}{l}\text { Predictable aspects of an } \\
\text { uncertain future }\end{array}$ & $\begin{array}{l}\text { Controllable aspects of an } \\
\text { unpredictable future }\end{array}$ \\
\hline Outcomes & $\begin{array}{l}\text { Competitive products for } \\
\text { existing markets }\end{array}$ & New products for new markets \\
\hline
\end{tabular}

An existing opportunity provides an entrepreneur with a possibility to run the process with causation-type reasoning. Creating an opportunity, in turn, is a process where an entrepreneur's effectuation-type actions bring the exploitation from her early aspirations towards more tangible goals.

Ojala reports in $[6,11]$ a longitudinal study on the business model creation of a Finnish ICT company. The study verifies empirically the opportunity exploitation theories $[1-3,10]$, stating that an opportunity creation is an iterative process, where the entrepreneur verifies the values of her actions by responses from the markets and adjusts the next steps accordingly. One of the key findings of Ojala $[6,11]$ is that an opportunity created once isn't necessarily stable, but needs further modifications driven by changes in technology, customer preferences, and markets. Based on the findings, Ojala presents an iterative model for business model creation and development [6].

The lean startup model [12] and the early-stage software startup development model [5] propose iterative processes to validate the business feasibility of an product idea. The validation is implemented in a build-measure-learn (BML) loop, the purpose of which is to identify a product with a problem-solution fit and a product-market fit.

\subsection{Prior Research on Human Capital Theory}

The HC theory [7] describes the effects of human capabilities and talents on the performance and success of human activities at many levels, ranging from individuals to nations, and finally to the mankind. Applied on entrepreneurship, the research on the HC theory studies individuals' and teams' contribution to a firm's business performance from the viewpoint of capabilities, knowledge, and talents [13].

Bosma et al. studied Dutch startups and found that investing on the entrepreneur's human and social capital had a significant effect on the startups' business performance [8]. Unger et al. [14], in turn, discovered that a priori existing capabilities and skills contributed more to the success of new enterprises than education or learning. Contrary findings were made by Martin et al. [15] indicating that entrepreneurship-specific education was a valid source of entrepreneurship-specific HC. 
Shrader and Siegel found that an enterprise's long-term performance was strongly affected by the fit between the enterprise's strategy and the team's experience, especially the team's technical experience [16]. Hatch et al. [17] found that gaining a team's experience from external sources reduced learning.

The relationship between an entrepreneur's HC and the radicalness of the innovation was studied by Marvel and Lumpkin [18]. The study divided the experience in two dimensions, the experience depth and the experience breadth, and concluded that the experience depth affected positively to the innovation radicalness while the experience breadth did not. Partly opposite result was concluded by Lazear indicating that entrepreneurs were generalists with several skills, but not necessarily experts in any specific area [19].

The results of the prior research manifest the importance of the entrepreneur's proper human capital for the success of a new enterprise. However, at a more detailed level they are mixed, giving reasoning for the objective of our study.

\section{$3 \quad$ Research Methods and Design}

To answer the research questions, we studied a group of software startups following the guidelines set up by Runeson and Höst for case study research in software engineering [20]. Runeson and Höst propose a five-step process: 1) designing the study, 2) preparing the data collection, 3) collecting the data, 4) analyzing the collected data, and $5)$ reporting. We opted to use interviews of key persons as the data collection method $[20,21]$ and a combination of thematic and narrative synthesis as the data analysis method [22], as presented in detail in the following sub-sections.

\subsection{Designing the Study}

The target group of our study were founders and other key persons of software startups. We interviewed eleven persons from twelve software startups, including one startup in Italy, two startups in Norway, and nine in Finland. Eleven case startups created own software-intensive products, while one offered software services. We contacted software startups in a snowballing process using local startup incubators as the starting point.

Table 3. Descriptions of the case founders.

\begin{tabular}{|l|l|l|l|}
\hline & Location & Product type & Founders \\
\hline A & Finland & Embedded product & Team of experienced professionals \\
\hline B & Italy & SW product & Mixed team of an experienced professional and students \\
\hline C & Norway & SW product & Team of just graduated \\
\hline D & Norway & SW product & Just graduated individual \\
\hline E & Finland & Embedded product & Internal startup team, experienced professionals \\
\hline F(a,b) & Finland & Embedded products & $\begin{array}{l}\text { a) Individual experienced professional, b) team of } \\
\text { experienced professionals }\end{array}$ \\
\hline G & Finland & SW product & Experienced professional individual \\
\hline H & Finland & SW product & Just graduated individual \\
\hline
\end{tabular}




\begin{tabular}{|l|l|l|l|}
\hline I & Finland & SW product & Team of experienced professionals \\
\hline $\mathrm{J}$ & Finland & Embedded product & Team of experienced professionals \\
\hline $\mathrm{K}$ & Finland & SW service & Team of experienced professionals \\
\hline
\end{tabular}

The founder $\mathrm{F}$ founded first a startup alone and then another as a team member. Both startups targeted to products for the health and fitness business segment, and we handle them in a single case. Out of eleven product-developing startups five had established businesses, two were discontinued, and four had functional prototypes under testing. The service provider had a ready service concept to offer.

\subsection{Collecting and Analyzing the Research Data}

The research data were gathered by utilizing semi-structured interviews and applying the key informant technique as defined in [21]. Most interviewees were founders or cofounders. One interviewee was a chief executive officer (CEO), who was hired to run the administration, but had a founder-level understanding of his company. The interviews were conducted face-to-face, recorded, and transcribed, following the thematic interview guides [23]. All interviews were held in English.

For the research data analysis we opted to use a combination of thematic synthesis and narrative synthesis, as presented in [22]. We started the analysis with a thematic synthesis utilizing the deductive approach, as presented in [24]. The initial codes of the deductive synthesis were derived from the research questions and from the utilized theories. The thematic synthesis was conducted by using NVivo11 tool. The list of the initial codes is shown in table $4 \mathrm{a}$.

Table 4a. Initial codes of the thematic synthesis.

\begin{tabular}{|l|l|}
\hline Code & Description \\
\hline Founders & Individual founder or a team \\
\hline Product & Product or service innovation \\
\hline Opportunity & Business opportunity \\
\hline Opportunity discovery & Discovery approach utilized \\
\hline Opportunity creation & Creation approach utilized \\
\hline Uncertainty & Type of experienced uncertainty and possible ways to manage it \\
\hline Opportunity realization & $\begin{array}{l}\text { Actions taken in the exploitation process of the opportunity, their } \\
\text { results, covering both the initial idea and its potential modifications }\end{array}$ \\
\hline Human capital & Founders' human capital \\
\hline Iteration count & $\begin{array}{l}\text { Complexity of the iterative opportunity exploitation process, including } \\
\text { pivoting [12] }\end{array}$ \\
\hline Learnings & Customer feedback and other lessons learned in exploitation \\
\hline
\end{tabular}

Coding with initial codes revealed that the founder's human capital consisted of several different areas, as proposed by [19]. Based on the initial findings we divided the human capital further to three more detailed codes, as shown in table $4 \mathrm{~b}$. 
Table 4b. Detailed codes of human capital.

\begin{tabular}{|l|l|}
\hline Human capital & Knowledge and understanding on .... \\
\hline HC on business & $\begin{array}{l}\text { the potential business, the customers, and the opportunity's value to } \\
\text { the customers }\end{array}$ \\
\hline HC on software development & software development needed when realizing the opportunity \\
\hline HC on application technology & application-specific technology other than software \\
\hline
\end{tabular}

The next step was a narrative synthesis of the research data, as presented in [22]. In the narrative synthesis, we broadened the view defined by the initial codes by two additional viewpoints, 1) the idea background, and 2) the refinements to the idea and the opportunity. In order to outline the strength of the human capital we defined a three level scale, as shown in table 5.

Table 5. Human capital scale for narrative synthesis.

\begin{tabular}{|l|l|}
\hline HC & Description \\
\hline Good & $\begin{array}{l}\text { The founder has earlier experience, good skills and knowledge on the } \\
\text { specific human capital area, is an expert }\end{array}$ \\
\hline Medium & $\begin{array}{l}\text { The founder has some experience, reasonable skills and knowledge } \\
\text { on the specific human capital area, but isn't an expert }\end{array}$ \\
\hline Limited & $\begin{array}{l}\text { The founder has no or little experience, missing skills and knowledge } \\
\text { on the specific human capital area }\end{array}$ \\
\hline
\end{tabular}

\section{$4 \quad$ Results}

In this section, we discuss the results of our study. The findings of the narrative syntheses are shown tables $6 \mathrm{a}$ and $6 \mathrm{~b}$, and summarized in the following.

Most of the founders were experienced professionals. In three cases the founder was a just-graduated person, though founder $\mathrm{H}$ had strong software knowledge and work experience in the customer organization. Even experienced founders had areas of limited or missing human capital. HC on software was the strongest area in our study group. Only three founding teams were good in all relevant $\mathrm{HC}$ dimensions.

Out of eleven cases we identified three partial opportunity creation and one full creation cases. All partial opportunity creation cases had also characteristics of opportunity discovery. The idea of case $\mathrm{F}$ was a totally new innovation. Failing in developing new technology was the main cause of the abandonment of the idea. Both iterative and linear opportunity exploitation processes were identified. The linear ones were tied to founders with good human capital, or to a fairly straightforward product.

All but two cases faced uncertainty during the opportunity exploitation process. We were able to identify three types of uncertainty sources, all typical for startups: 1) problems with technology, 2) problems with customer and markets, and 3) problems with funding. In four cases the application-specific technology was the biggest source of the uncertainty. Not being able to identify and hire competent personnel for software development was the main cause of uncertainty in three cases. Creating the customer base was uncertain in two cases. The main means to cope with the technology-related 
uncertainty were iteration and networking. Funding uncertainty was tackled by deploying a variety of funding sources.

Table 6a. Summary of the findings of startups A, B, C, D, E, F

\begin{tabular}{|c|c|c|c|c|c|c|c|c|c|c|c|c|c|c|}
\hline$\Leftrightarrow$ & 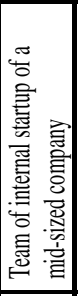 & 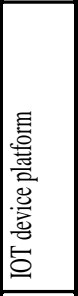 & 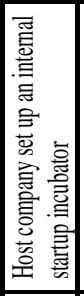 & 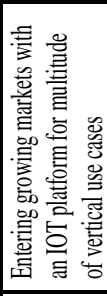 & 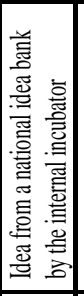 & & 总 & 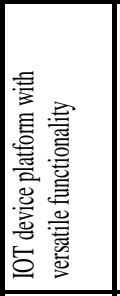 & 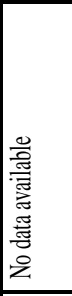 & 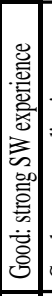 & 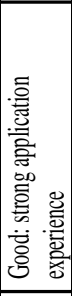 & 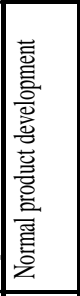 & 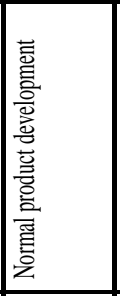 & 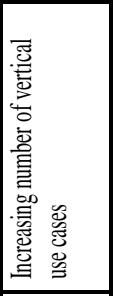 \\
\hline - & 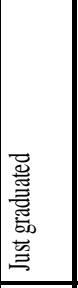 & 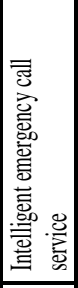 & 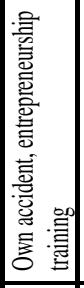 & 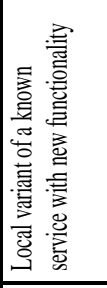 & 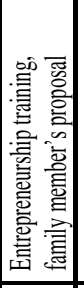 & & 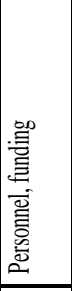 & 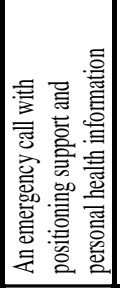 & 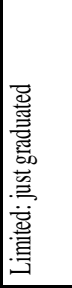 & 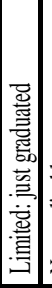 & 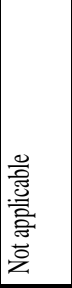 & 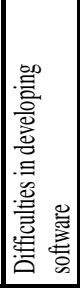 & 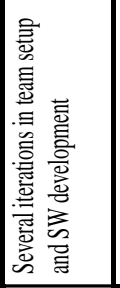 & 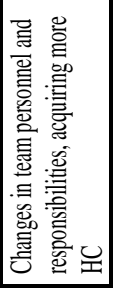 \\
\hline . & 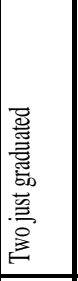 & 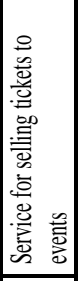 & 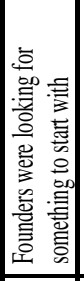 & 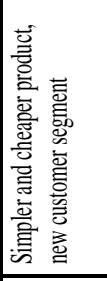 & 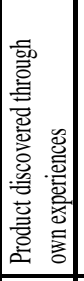 & & 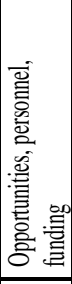 & 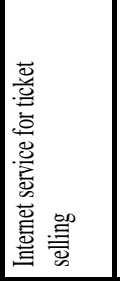 & 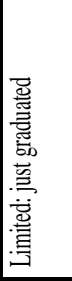 & 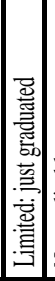 & 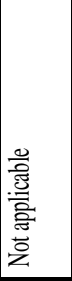 & 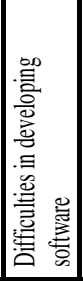 & 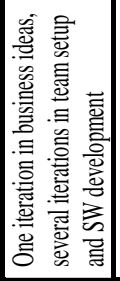 & 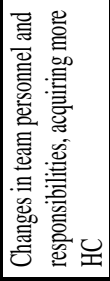 \\
\hline$\infty$. & 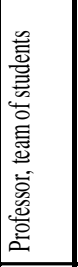 & 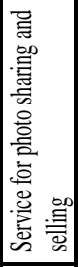 & 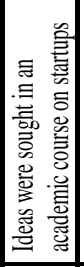 & 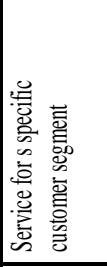 & 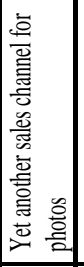 & & 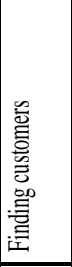 & 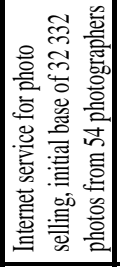 & $\overrightarrow{.}$ & 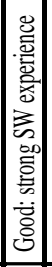 & 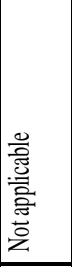 & 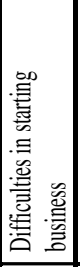 & 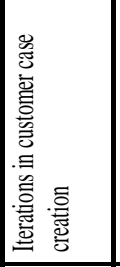 & 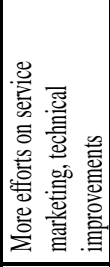 \\
\hline 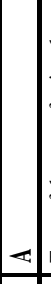 & 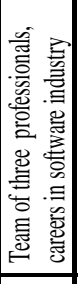 & 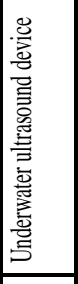 & 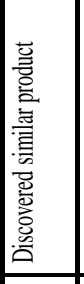 & 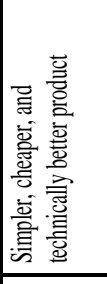 & 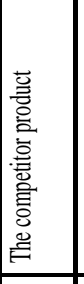 & 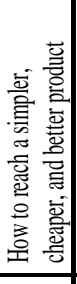 & 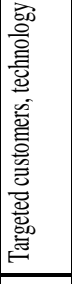 & 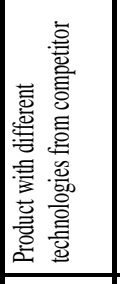 & 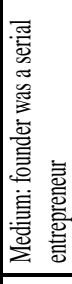 & 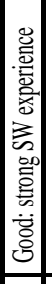 & 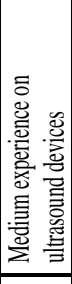 & 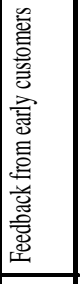 & 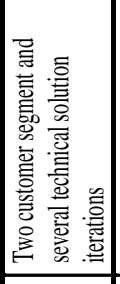 & 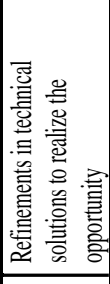 \\
\hline : & t5 & 总 & 亲 & 言 & 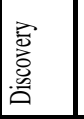 & & 善 & 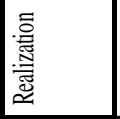 & 旁 & $\begin{array}{l}n \\
0 \\
0 \\
0\end{array}$ & & 产 & 言 & 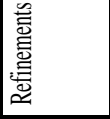 \\
\hline
\end{tabular}


Table 6b. Summary of the findings of startups G, H, I, J and K

\begin{tabular}{|c|c|c|c|c|c|c|c|c|c|c|c|c|c|c|}
\hline & 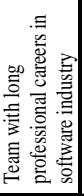 & 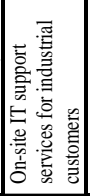 & 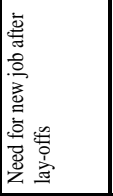 & 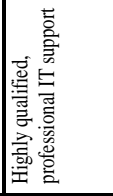 & 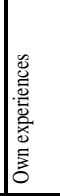 & & 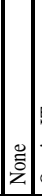 & 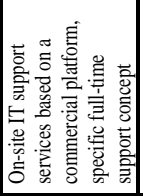 & 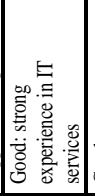 & 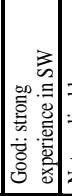 & 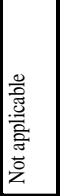 & 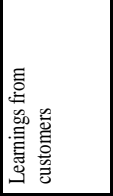 & 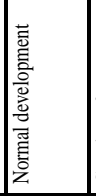 & 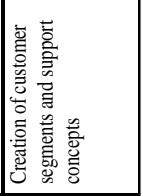 \\
\hline & 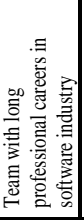 & 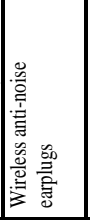 & 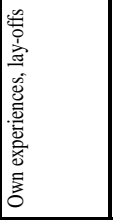 & 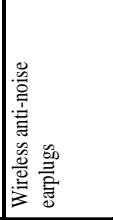 & 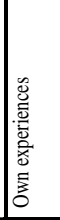 & 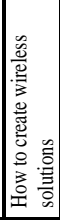 & . & 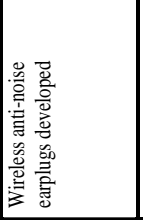 & 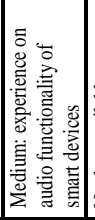 & 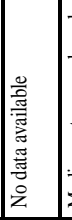 & 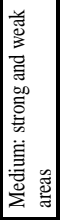 & 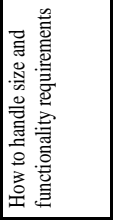 & 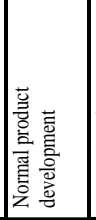 & 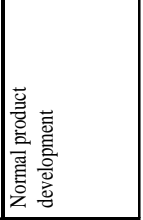 \\
\hline & 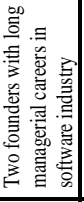 & 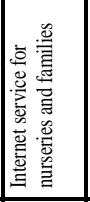 & 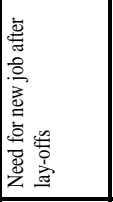 & 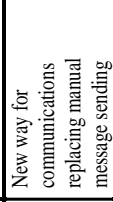 & 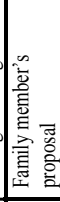 & & 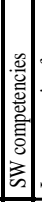 & 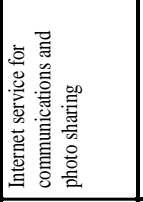 & 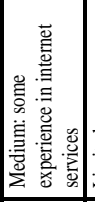 & $\begin{array}{l} \\
\\
\end{array}$ & 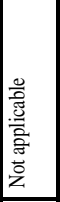 & 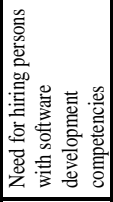 & 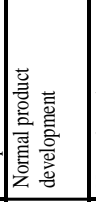 & 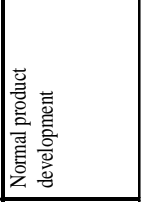 \\
\hline \pm & 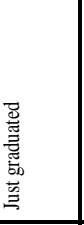 & 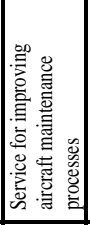 & 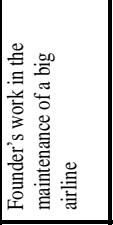 & 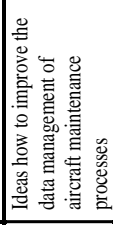 & 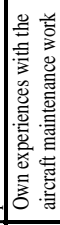 & & 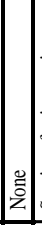 & 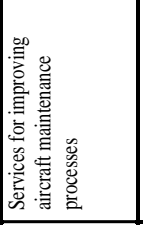 & 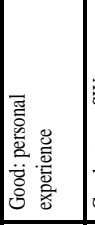 & 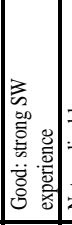 & 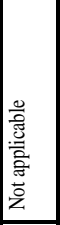 & 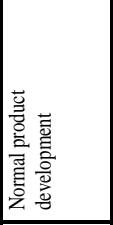 & 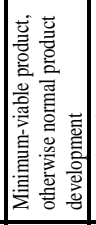 & 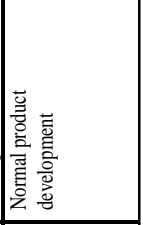 \\
\hline & 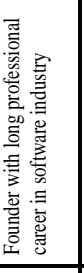 & 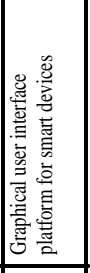 & 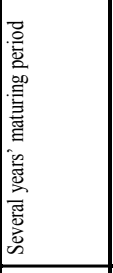 & 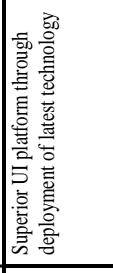 & 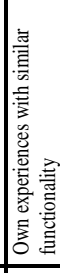 & 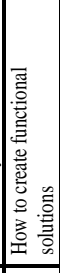 & & 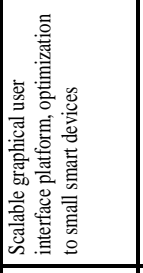 & 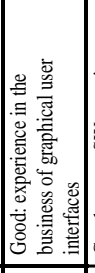 & 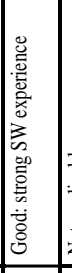 & 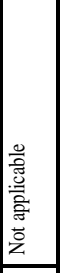 & 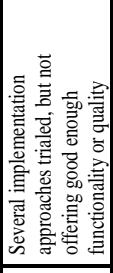 & 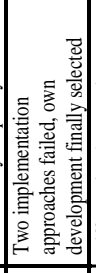 & 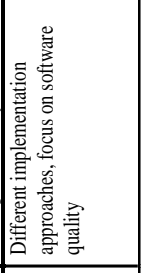 \\
\hline & 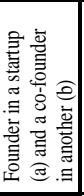 & 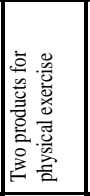 & 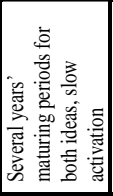 & 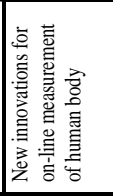 & 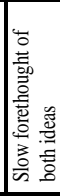 & 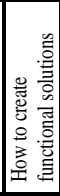 & & 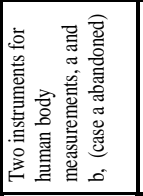 & 总 & 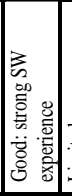 & 总 & 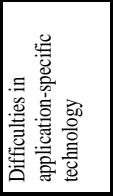 & 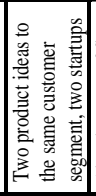 & 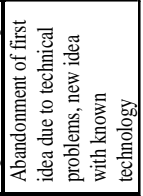 \\
\hline & 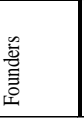 & 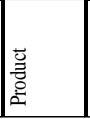 & 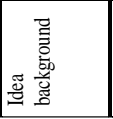 & \begin{tabular}{|l} 
㐔 \\
言 \\
言
\end{tabular} & 总 & 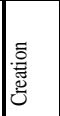 & & 宽 & 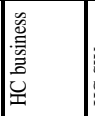 & $\begin{array}{l}3 \\
\vdots \\
0 \\
\vdots \\
x\end{array}$ & 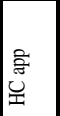 & 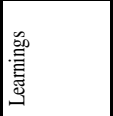 & 参 & 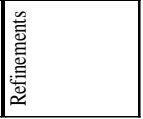 \\
\hline
\end{tabular}

\section{Discussion}

In this section, we first present the answers to the research questions and discuss our findings in the context of the opportunity exploitation theories $[1-3,10,6]$ and human capital theory [8, 14, 16-19], [8,14, 16-19]. Then follows the discussion on the validity of our findings, and their relevance to the academia and to practitioners. 


\subsection{Answering the Research Questions}

RQ1: What are the characteristics of the software startups' opportunity exploitation processes?

In several cases of our study we could identify characteristics of both opportunity creation and discovery processes $[1,2]$, as well as characteristics of effectuation and causation $[3,10]$. Out of eleven cases we categorized four as creation processes. In all four cases the opportunity was to create business by new, ambitious technical solutions that were not existing without the founders' actions. From the business perspective cases $\mathrm{A}, \mathrm{G}$ and $\mathrm{J}$ were, however, fairly clear opportunity discovery cases, because the products were targeted to existing markets with existing products. The innovation of case $F(a)$ was such a new one that even the business case was uncertain.

Out of the seven opportunity discovery cases, five showed clear characteristics of discovery. In those cases the opportunity was existing independently of the founders: similar products were existing and the opportunity was tied to development of a new product for different customer segments or simply to development of competitor to well-known but growing markets. Cases B and H were different. In case B the product was not a new one, neither its development turned out to be technically challenging. However, the exploitation process turned to a creation-type one on the business side. In case $\mathrm{H}$ the product was a unique one targeted for a unique customer. There were no similar products nor competitive imperfections, but the exploitation process created a new slot in the business environment [1]. However, it was a most typical opportunity discovery process with an alert individual, a predictable outcome, and the uncertainty tackled already before founding the enterprise by a successful minimum-viable-product [12].

RQ2: What are the effects of the founders' human capital on the opportunity exploitation processes?

The human capital of the founders of our case startups varied from very strong to weak. $\mathrm{HC}$ on software was the most common good $\mathrm{HC}$ dimension. $\mathrm{HC}$ on business and on application-specific technology could be limited also in cases of founders with a good $\mathrm{HC}$ in software.

In our cases existing or missing $\mathrm{HC}$ was not identified as a direct determining factor between the initial opportunity creation and discovery. Out of the four opportunity creation cases, only one founder had a strong expertise in all relevant $\mathrm{HC}$ dimensions. Similarly, in cases with opportunity discovery, the founders' HC compositions varied from limited to good in all three HC dimensions.

The founders' HC profiles had a strong correlation with the uncertainty and the iterative nature of the opportunity exploitation process. Missing $\mathrm{HC}$ in a certain HC dimension tended to predict iterative processes, and good HC linear processes, though there were variations to both directions.

Compensation for the missing $\mathrm{HC}$ was common in our research group. The research data reveal that the typical compensation means varied between the HC dimensions: 1) in case of business $\mathrm{HC}$ a common compensation was based on networking, 2) in case 
of software $\mathrm{HC}$ on hiring qualified work force, and 3) in case of application $\mathrm{HC}$ on networking and learning by iterating.

\subsection{Findings on Opportunity Exploitation in Software startups}

Our categorization of cases to creation and discovery, presented in section 5.1 , is a simplifying overview based on the direction a particular case tends to incline. More significantly, our results indicate that in a practical situation the opportunity creation and discovery characteristics co-exist in the very same opportunity exploitation process - not only offer two explanation models of it. The founders' actions according to a specific theory and utilizing a specific reasoning model seems to be a context-dependent and situational choice varying over the topics of the opportunity exploitation process.

The uncertainty, mentioned as a differentiator between opportunity creation and discovery in [1], was identified in both creation and discovery cases. What are then the factors causing the uncertainty, and leading to a parallel deployment of creation and discovery processes?

We seek the answer by taking a look on the iteration, learnings and refinements rows of tables $6 \mathrm{a}, 6 \mathrm{~b}$, and $6 \mathrm{c}$. The cases with a linear development process and learnings and refinements along to a normal product development carried characteristics of opportunity discovery processes. Excluding case I, the cases were characterized by founders being relatively good in relevant $\mathrm{HC}$ dimensions, business, software, and application. In case I the founders could compensate for their HC shortages through networking and recruitment, leading to a linear opportunity exploitation process.

Excluding case $\mathrm{G}$, the iterative cases were characterized by shortages in one or several human capital areas. In case $\mathrm{G}$ the founder had strong experience in all relevant $\mathrm{HC}$ dimensions. He needed, however, three iteration rounds to figure out the technology solutions that fulfilled the functionality and quality targets he defined for the product.

The research data coded as learnings reveal that in the cases with a linear development process the learnings were such experiences from own actions and customers that are typical in a managed product development. In the iterative cases, in turn, the learnings were related to the founders' shortages in one or several HC dimensions.

Our findings gave a mixed picture of the nature of the entrepreneurs compared to the non-entrepreneurs. The opportunity discovery theory assumes that the entrepreneurs are more alert to the existing opportunities than non-entrepreneurs, while the creation theory points out the entrepreneurs' focus on contingencies [1]. The research data reveal that all founders but two were actively looking for new opportunities, but the level of alertness, sources of the ideas, and focus on contingencies varied.

By combining two crucial elements of a software startup's early stages, the business opportunity and the founders' capabilities to exploit it, our study deepen the knowledge on how software startups are created. It gives new perspectives to Ries' lean startup model [12], which has in the recent years gained popularity among the startup researchers. It indicates that iterative learning, as proposed by the lean startup model's build-measurement-learn cycle, happens not only in the customer interface but also internally in a startup, covering both the business-related and the technical aspects. 


\subsection{Effects of Human Capital on Opportunity Exploitation in Software Startups}

The results of our study are in line with the results of studies on the human capital [8, $14,16]$, pointing out the value of the entrepreneur's HC to the startup's business performance. The entrepreneur's good HC in relevant areas seems to make the opportunity exploitation process smoother and faster, which in turn lays a better basis for the enterprise's overall success and performance. The results do not, however, support the findings of [17], claiming that $\mathrm{HC}$ from external sources would be less valuable for startups. Instead, in our cases $\mathrm{HC}$ from external sources seemed to be a common and successful compensation for the founders' $\mathrm{HC}$ shortages.

We could identify the two dimensions of HC pointed out in [18], HC depth and breadth. From the perspective of $\mathrm{HC}$, our results indicate that shortages in any $\mathrm{HC}$ dimension of our study increase uncertainty and iteration. The findings of [19], indicating that entrepreneurs are generalists without being experts in any specific area, were not fully supported in our study.

We could identify the unbalance between the human capital and the challenges as the key reason for the uncertainty. Especially clear the relationship was in cases where challenging application-specific technology was needed. In two cases, the founders' $\mathrm{HC}$ shortages prevented them from hiring competent software development resources, which was then the key source of the uncertainty.

The above reveals two items in our research determining between opportunity creation and discovery as well as between effectuation and causation: 1) the founders' own human capital, and 2) their possibilities to compensate for the shortages. As long as there are $\mathrm{HC}$ shortages the exploitation process tends to be iterative and follow the characteristics of the opportunity creation $[1-3,10]$ - independently of whether the opportunity originally was an existing discovered one, or a created one. Correspondingly good, available $\mathrm{HC}$ tends to direct the exploitation process towards the opportunity discovery type $[1-3,10]$.

\subsection{Validity Discussion}

We discuss the validity of our findings from four viewpoints, construct validity, internal validity, external validity, and reliability [20].

The construct validity concerns whether the operational measures that are studied really represent what the researcher has in mind and what is investigated according to the research questions [20]. We conducted our study by using well-established research methods for qualitative research. We used semi-structured interviews of the founders of software startups for gathering the research data [21]. The interviews and data analysis were conducted by the first author. His over thirty years' long career in software industry helped him to analyze the interview data in accordance with the real characteristics of the study cases.

The internal validity concerns examination of causal relations [20]. When studying whether a factor effects the investigated factor, other uncontrolled, possibly unknown factors may affect the investigated factor and threaten the internal validity of the 
research [20]. From our research data, we were able to identify a relationship between an iterative exploitation process and the shortages in the founders' human capital. There may be, however, other factors leading to an iterative exploitation process, not covered in this research. Therefore, we can only conclude that missing human capital seems to be one source of uncertainty.

The external validity concerns the generalizability of the findings [20]. The limited amount of study cases restricts the external validity of our findings, though the research covered a fairly broad palette of different cases in several geographical locations.

Reliability concerns the dependency of the data and analysis on the specific researcher [20]. To address the reliability issues we utilized peer work in our study. The interview schema was created together with two experienced researchers. All interview data was recorded, and the data was transcribed by an external transcription service. Analyzing the data and concluding the findings was done by the first author and reviewed by the co-authors.

\subsection{Relevance to Academia and Practitioners}

We studied the early stages of software startups, identifying and exploitation the business opportunities, from the perspective the founders' human capital, their capabilities, knowledge, and experience. Our research had an empirical focus, studying the real-life embodiments of the utilized theories. Our results give the academia new interesting research perspectives by indicating that the two theoretical approaches for opportunity exploitation, creation and discovery processes [1], co-exists in the early stages of the same software startup. In our study, we focused on the founders' human capital as a factor affecting the deployment of these two processes. Our study gives a model for future studies of other factors affecting opportunity exploitation in software startups.

By having a practical focus our study provides new entrepreneurs with in-depth knowledge on how to bring a discovered opportunity or an opportunity aspiration towards more tangible ideas and products. Our study indicates that a successful exploitation of an opportunity requires a broad palette of technical and business-related human capital. It points out that an entrepreneur needs access to that human capital, and proposes that networking, hiring capable work force, and learning by iterating are the basic means to gather it.

\section{Conclusions and Future Research}

In this study we empirically explored how a group of software startup founders exploited the opportunities, on which the founders were building their startups. We utilized the multiple-case study method, collecting the research data from semistructured interviews of the founders or founding team members. We identified embodiments of both the opportunity creation and discovery theories in the same opportunity exploitation processes. We found that missing human capital was a reason for the uncertainty typical for opportunity creation and effectuation cases. We further 
identified that the uncertainty caused by missing human capital was tackled by networking, hiring capable work force, and learning by iterating.

Our results indicate that the deployment of either the opportunity creation or the discovery processes was context-dependent and situational, varying not only between the case founders, but also between different problem areas of the same process.

The case startups were all located in West-Europe. Studies with bigger sample sizes and geographical coverage would be necessary to validate and generalize our results. Studies seeking for other factors effecting the deployment of the opportunity discovery and creation processes, would deepen the knowledge gathered in this study.

Acknowledgments. This study was partly funded by TEKES as part of the HILLA program. We thank the members of the Software Startups Global Research Network that supported this study, especially Anh Nguyen Duc and Pekka Abrahamsson for their help in gathering the empirical data.

\section{References}

1. Alvarez, S.A., Barney, J.B.: Discovery And Creation: Alternative Theories of Entrepreneurial Action. Strategic Entrepreneurship. 26, 11-26 (2007).

2. Alvarez, S.A., Barney, J.B., Anderson, P.: Perspective--Forming and Exploiting Opportunities: The Implications of Discovery and Creation Processes for Entrepreneurial and Organizational Research. Organization Science. 24, 8-13 (2012).

3. Sarasvathy, S.D.: Causation and effectuation: Toward a theoretical shift from economic inevitability to entrepreneurial contingency. Academy of Management Review. 26, 243-263 (2001).

4. Ries, E.: The Lean Startup. Crown Business. 1-28 (2011).

5. Bosch, J., Olsson, H.H., Björk, J., Ljungblad, J.: The early stage software startup development model: a framework for operationalizing lean principles in software startups. In: Lean Enterprise Software and Systems. pp. 1-15. Springer (2013).

6. Ojala, A.: Business models and opportunity creation: How IT entrepreneurs create and develop business models under uncertainty. Information Systems Journal. 26, 451-476 (2016).

7. Becker, G.S.: Human Capital: A Theoretical And Empirical Analysis, With Special Reference To Education, (1993).

8. Bosma, N., Van Praag, M., Thurik, R., De Wit, G.: The Value of Human and Social Capital Investments for the Business Performance of Startups. Small Business Economics. 23, 227-236 (2004).

9. Becker, G.: Human Capital Revisted. Journal of Chemical Information and Modeling. 53, 1689-1699 (1994).

10. Sarasvathy, S.D.: Effectuation: Elements of entrepreneurial expertise. Edward Elgar Publishing (2009).

11. Ojala, A.: Discovering and creating business opportunities for cloud services. 
Journal of Systems and Software. 113, 408-417 (2016).

12. Ries, E.: The lean startup: How today's entrepreneurs use continuous innovation to create radically successful businesses. Random House LLC (2011).

13. Hitt, M.A., Bierman, L., Shimizu, K., Kochhar, R.: Direct and moderating effects of human capital on strategy and performance in professional service firms: aresource-based perspective. Academy of Management Journal. 44, 1328 (2001).

14. Unger, J.M., Rauch, A., Frese, M., Rosenbusch, N.: Human capital and entrepreneurial success: A meta-analytical review. Journal of Business Venturing. 26, 341-358 (2011).

15. Martin, B.C., McNally, J.J., Kay, M.J.: Examining the formation of human capital in entrepreneurship: A meta-analysis of entrepreneurship education outcomes. Journal of Business Venturing. 28, 211-224 (2013).

16. Shrader, R., Siegel, D.S.: Assessing the relationship between human capital and firm performance: evidence from technology-based new ventures. Entrepreneurship Theory and Practice. 31, 893-908 (2007).

17. Hatch, N.W., Dyer, J.H.: Human capital and learning as a source of sustainable competitive advantage. Strategic Management Journal. 25, 1155-1178 (2004).

18. Marvel, M.R., Lumpkin, G.T.: Technology entrepreneurs' human capital and its effects on innovation radicalness. Entrepreneurship Theory and Practice. 31, 807-828 (2007).

19. Lazear, E.P.: Balanced Skills and Entrepreneurship. The American Economic Review. 94, 208-211 (2004).

20. Runeson, P., Höst, M.: Guidelines for conducting and reporting case study research in software engineering. Empirical software engineering. 14, 131-164 (2009).

21. Marshall, M.N.: The key informant technique. Family Practice. 13, 92-97 (1996)

22. Cruzes, D.S., Dybå, T., Runeson, P., Höst, M.: Case studies synthesis: a thematic, cross-case, and narrative synthesis worked example. Empirical Software Engineering. 1-32 (2014).

23. Lethbridge, T.C., Sim, S.E., Singer, J.: Studying software engineers: Data collection techniques for software field studies. Empirical software engineering. 10, 311-341 (2005).

24. Cruzes, D.S., Dybå, T.: Recommended steps for thematic synthesis in software engineering. In: International Symposium on Empirical Software Engineering and Measurement. pp. 275-284. IEEE (2011). 